\title{
Expecting moral philosophers to be reliable
}

Article

Accepted Version

Andow, J. (2015) Expecting moral philosophers to be reliable. Dialectica, 69 (2). pp. 205-220. ISSN 1746-8361 doi: https://doi.org/10.1111/1746-8361.12092 Available at https://centaur.reading.ac.uk/42079/

It is advisable to refer to the publisher's version if you intend to cite from the work. See Guidance on citing.

Published version at: http://dx.doi.org/10.1111/1746-8361.12092

To link to this article DOI: http://dx.doi.org/10.1111/1746-8361.12092

Publisher: Wiley

All outputs in CentAUR are protected by Intellectual Property Rights law, including copyright law. Copyright and IPR is retained by the creators or other copyright holders. Terms and conditions for use of this material are defined in the End User Agreement.

\section{www.reading.ac.uk/centaur}

\section{CentAUR}

Central Archive at the University of Reading

Reading's research outputs online 


\title{
Expecting Moral Philosophers to be Reliable*
}

\author{
James Andow \\ University of Reading
}

\begin{abstract}
Are philosophers' intuitions more reliable than philosophical novices'? Are we entitled to assume the superiority of philosophers' intuitions just as we assume that experts in other domains have more reliable intuitions than novices? Ryberg raises some doubts and his arguments promise to undermine the expertise defence of intuition-use in philosophy once and for all. In this paper, I raise a number of objections to these arguments. I argue that philosophers receive sufficient feedback about the quality of their intuitions and that philosophers' experience in philosophy plausibly affects their intuitions. Consequently, the type of argument Ryberg offers fails to undermine the expertise defence of intuition-use in philosophy.
\end{abstract}

\section{Introduction}

Are philosophers' intuitions more reliable than the intuitions of people who are not philosophically trained? This question is important to philosophy. Recent empirical work has been argued to show that intuitions in general are rather unreliable (see, e.g., Zamzow and Nichols, 2009, who cite a number of studies showing worrying effects in moral intuitions). So, widespread use of intuition-based reasoning in philosophy is arguably problematic. ${ }^{1}$

Ryberg (2013) argues against a version of the expertise defence of the reliability of intuitions in philosophy. The focus of his arguments is the use of intuitions in moral philosophy. However, his arguments apply fairly generally. The expertise defence relies upon a positive answer to our opening question. The empirical work on intuitions largely involves the use of participants with little or no philosophical training. So, if good reason

\footnotetext{
This paper is forthcoming in Dialectica. This is a personal copy of the accepted paper. Please cite the official version as page numbers will be different and some small changes may have been made. 1 Other evidence raises distinct important worries about the reliability of intuitions. For example, evidence suggests that in certain cases the intuitions of laypeople may differ significantly from the intuitions of philosophers, see, e.g., Buckwalter 2010; Cova and Pain 2012 (see also the debate between Cohen and Nichols 2010, and Roberts et al. 2014). If that is right, unless reason can be given for thinking that philosophers' intuitions are more reliable than those of laypeople (in these cases), the evidence raises doubts as to whether philosophers should continue to trust their own intuitions (in the relevant domain). The expertise defence considered in this paper is one that aims to respond to worries generated by both types of finding (evidence of instability of intuitions, and evidence of differences between the intuitions of novices and philosophers).
} 
can be given to expect philosophers' intuitions to be more reliable, the challenge can be resisted, for the intuitions which actually get used in philosophy are typically those of philosophers - so is the thought.

There are a number of ways of advancing the expertise defence. Ryberg considers an analogical version. The analogy is supposed to be as follows. Mathematics and chess experts, for example, have great prior experience in their field. And, it is on this basis we expect their intuitive judgements to be more reliable than those of novices. Experts in philosophy have much greater experience in their field than philosophical novices. So, it is sensible to expect philosophers' intuitions to be more reliable. Ryberg argues this is not the case, at least with respect to moral philosophers. Ryberg argues that the founding of the expectation - that experts' intuitions will be more reliable - upon experts' greater prior experience uses two implicit assumptions: the causality assumption and the quality assumption. Ryberg argues that neither assumption is granted when considering moral philosophy, and his arguments apply with some generality to much of philosophy.

So, Ryberg's argument is important. His line of attack against the expertise defence has the potential to undermine appeals to philosophers' expertise in defence of intuition-use once and for all. If there are no good grounds to assume philosophers' greater reliability, then evidence that novices' intuitions are unreliable should be very worrying for advocates of intuition-use. However, I argue, Ryberg's arguments fail. I argue we may grant both the causality and quality assumptions. By doing so, I provide a limited defence of the expertise defence. Any debate about the merits of the expertise defence needs to focus elsewhere. If the expertise defence fails, it is not for the reasons Ryberg provides. ${ }^{2}$

\section{The Causality Assumption}

The causality assumption is that experts' intuitions are the result of their prior experiences. Grandmasters and mathematicians, for example, have different intuitions than novices in part because they have a wide experience of playing chess and mathematical problem-solving respectively. Their prior experience plays a causal role in shaping their capacities for intuitive judgement. Ryberg argues that prior experience doesn't play this role in moral philosophy.

It is worth making a couple of notes about how I understand the causality assumption. I think the relevant question is whether there is a causal link between intuitive capacities and experience; the expertise defence is implausible unless experience in a field plausibly changes one's intuitions about that field. However, I need to say something in defence of this understanding. The reason for this is that Ryberg himself draws a distinction between two types of causal link - shaping and generating links - and explicitly distances his discussion from the issue of whether philosophers' intuitions are shaped by their experience (Ryberg, 2013, n.7). Since I won't be doing the same, I should say why.

Ryberg thinks the important issue is whether experts' previous experience generates their intuitions rather than whether it shapes them. Before we consider his reasons for thinking this is the important issue, we first need to consider what this distinction is supposed to amount to. In what sense are mathematicians' and grandmasters' intuitions plausibly generated by their experience? It is not completely obvious how Ryberg intends the distinction to be understood. However, it seems likely the idea is that mathematicians and grandmasters have intuitive capacities which novices do not. The idea seems to be

$\overline{2}$ See Rini (2014) for a rather different critical response to Ryberg's paper. 
that experts in mathematics and chess have new capacities which have been caused to be by their previous experience rather than capacities that they share with novices which have been changed by experience. Ryberg thinks this is the most plausible story as to how mathematicians and grandmasters have different intuitions than novices. I should note that I am doubtful as to whether this is the more plausible story, given that, as Ryberg admits, novices in chess and mathematics can and do have some, albeit weak and vague, intuitions. However, for the sake of argument, let's grant Ryberg this claim.

The question now is why one should think that the expertise defence could only be founded by the plausibility of a generating causal link between philosophers' experience and intuitions. Why couldn't the plausibility of a shaping link do the job? Ryberg considers this objection to his approach to the causality assumption (Ryberg, 2013, n.7, p.7). But his response is not persuasive. Ryberg argues that, if one holds that philosophers' intuitions are plausibly shaped (but not generated) by their experience,

then it is no longer clear that the standard analogies (to mathematics or chess) hold: in these cases intuitions are most plausibly explained as generated by experience.

As I have noted, I am doubtful about the idea that intuitions are plausibly generated by experience in mathematics and chess. However, even if mathematicians' and grandmasters' intuitions are generated, I don't understand why this would threaten the analogy. Not all features of the causal link between experience in mathematics/chess and intuitions are relevant to the analogy. I can see no reason to think the supposed fact that the link in mathematics/chess is a generating one is a relevant one. Appreciating that his response will not be persuasive, Ryberg makes two further points (Ryberg, 2013, n.7): (i) he argues that, even if mere shaping is sufficient (for the satisfaction of the causality assumption), it isn't clear how one could maintain that philosophers' experience shapes their intuitions; (ii) even if the defender of the expertise defence can show that philosophers' intuitions are shaped by their experience, they also need to respond to the arguments he raises concerning the quality assumption. In the following, my discussion addressed both these points. In section 3, I demonstrate that philosophers' experience shapes their intuitions, and, in section 5, I respond to his arguments against the quality assumption.

\section{In Defence of the Causality Assumption}

In challenging the idea that there is a causal link between experience and intuitions in moral philosophy, Ryberg considers the example of a reductio argument that the utilitarian approach to punishment should be rejected because it has a counterintuitive implication: framing an innocent person can be right if sufficient suffering can be thereby avoided. Ryberg correctly argues it is implausible this intuition is based on prior experiences involving reductio arguments. While he concedes these are not the only previous experiences which might influence philosophers' intuitions, he thinks instead that it is most plausible that moral intuitions are genetic or otherwise innate. The support he offers for this is that, while novices in chess and mathematics have only vague intuitions or fail to have any intuitions at all, philosophical novices have just as many and just as strong intuitions as philosophers. Ryberg uses inference to the best explanation and concludes: intuitions in chess and mathematics are caused by experience - explaining why those with little experience fail to have (strong) intuitions - and, since they don't 
exhibit this pattern, moral intuitions don't come from experience but are likely genetic or otherwise innate. But this isn't the best explanation (although I wouldn't want to deny that intuitions have any such component).

Ryberg's mistake is that he simply fails to consider the most obvious account of how experts' intuitions might be the (partial) product of their previous experience. Here's a simple-headed picture. Grandmasters and mathematicians, for example, have different intuitions than novices in part because they have a wide experience of playing chess and mathematical problem-solving respectively. Now consider, as Ryberg encourages, "the intuition of the philosopher who, for the first time, is confronted with a punishment-ofthe-innocent scenario' (Ryberg, 2013, p.6). What previous experiences of the philosopher might we think could found the philosophers' putative greater reliability? The obvious candidates are those experiences she has of having considered structurally or thematically similar cases: those involving systemic injustice, punishment of innocents, politically motivated trials, etc.

This may be less obvious in other philosophical domains. Cases with moral content are easy to find in newspapers. Other philosophically interesting cases may seem less easy to find. So let me say something about the sorts of cases I have in mind. What previous experiences of thematically and structurally similar cases do I think plausibly influence philosophers' intuitions? I'll use a simple headed genealogy of complicated cases. Complicated cases build on simple ones. One doesn't typically have an intuition about a very complicated example without some prior experience of similar slightly simpler cases. Complicated fake barn cases (Gendler and Hawthorne, 2005) build on simple fake barn cases (Goldman, 1976) and Gettier cases (Gettier, 1963), for example, which build on yet simpler cases such as Socrates' case of a jury being persuaded by a lawyer (Burnyeat and Barnes, 1980). Complicated cases involving finks and antidotes build on simpler cases involving powers and dispositional properties (Lewis, 1997). Complicated thought experiments involving populations of mice who evolve big ears and end up living in environments where their ears resemble food (see Walsh, 1996) are typically not encountered by people who have no experience of thinking about biological function and evolution, etc. And, the simplest cases, upon which the complicated ones build, are such that the philosopher first encountering them could have encountered them in a newspaper. One doesn't come to epistemology without some familiarity with knowledge attributions. One doesn't come to metaphysics without having considered a statue or two and their destruction. And, since beginning with simple everyday cases, expert philosophers have had a lot of experience with complicated and tricky cases, and have given them the particular attention to details which comes with consideration in the philosophy classroom and in the research community.

If you are looking for some feature of philosophers' experiences and training that has plausibly affected the intuitions which they have, about the sorts of cases they consider, then the natural place to start is the large portion of philosophers' careers spent considering counterfactual scenarios, thought-experiments, etc. Once you realise this, it is no mystery why philosophical novices have more and stronger intuitions than novices in chess and maths. They are not as new to the game as novice mathematicians and chess players, who may never have encountered proofs or played chess. Normal people have encountered unjust punishment at close quarters since infancy, so they are perfectly equipped to have strong intuitions about moral cases (although this is not to say that they have the same amount of relevant experience as professional ethicists). This point doesn't only apply to simple 'newspaper cases', it extends to more complicated cases too. 
Take a bizarre trolley case and a chess problem. Suppose that they are both incredibly complex (and equally so). It is surely true that the novice may be expected to have some (albeit, perhaps, weak/unclear) intuitions about the trolley case, but will probably fail to have any intuitions at all about the chess problem. Given my suggested story, this is to be expected. Philosophical novices are not as new to the game. They really have a much greater experience with simple cases than novice chess players who have next to no such experience. This affords novices significantly better purchase on more complicated philosophical cases than on more complicated mathematical issues or chess problems. And so, while novice mathematicians fail to have any intuitions at all about complex cases, novice philosophers should be expected to have some intuitions. Nothing Ryberg says detracts from the plausibility of this story, and so nothing he says should shake our confidence in the causality assumption, even restricted to the moral domain.

\section{The Quality Assumption}

Even if philosophers' experience moulds their intuitions, this is no guarantee it moulds them for the better, rather than in epistemically irrelevant or deleterious ways. It is only plausible that any moulding which goes on helps refine experts' intuitions if experts receive sufficient feedback about the quality of their intuitions.

It is worth taking a moment to consider exactly what the quality assumption is supposed to be. Ryberg introduces the quality assumption thus,

... the step from experience to expertise presupposes that the activity in question is assessable on some sort of quality parameter. (p.7)

The idea is that there must be some intuition-independent source of information about the quality of our intuitions. ${ }^{3}$ This is an assumption Ryberg thinks is clearly met in the case of mathematicians and grandmasters. Mathematicians have experience of engaging in correct mathematical proofs; grandmasters, of making moves in games they won. This type of experience is what makes it plausible mathematicians and grandmasters learn from their previous experience. Ryberg thinks the quality assumption cannot be granted in the case of moral philosophy, and the considerations he offers seem to extend to philosophy more generally. Why does Ryberg think the quality assumption can't be granted? Well, he identifies some specific experiences he thinks philosophers typically lack.

It is ... not a correct description of a philosopher's prior experiences to hold that she has been through numerous cases in which she started out, say, by rejecting a moral position because it had a counter-intuitive implication and then, subsequently, found out that the rejection of this position was in fact correct. ... while there exists an intuition-independent criterion for the assessment of mathematical proofs and success in chess, this is usually not the case with regard to moral theory. (Ryberg, 2013, p.8)

$3 \quad$ Ryberg sometimes talks in rather different terms. For instance, the quoted section is followed immediately by, "If it, for a certain activity, does not make sense to talk of being better or worse, then neither does it make sense to talk of someone as being an expert in this activity" (Ryberg, 2013, p.7). This might suggest that Ryberg is going to argue that it doesn't make sense to talk about intuitions about (moral) philosophy being better or worse. This can't be Ryberg's aim. One obvious way a person's intuitions might be better than another's is to be more reliable (or to have a greater proportion of true intuitions). Ryberg doesn't do anything to argue against this claim. 
Ryberg argues that there are no such sources from which one might receive feedback in (moral) philosophy. Similar suspicions lie at the heart of other worries about intuition, e.g., worries about calibration initiated by Cummins (1998) and developed by Weinberg et al. (2012). Stich (2010) also raises similar worries saying that there is obviously no way to check philosophers' intuitions about, for instance, Gettier cases that compares to the way one can check the judgements of trained radiologists using surgery or autopsy.

In the following, I argue that it is wrong to think that the quality assumption cannot be granted in philosophy. That said, I don't dispute the fact that philosophers rarely (if ever) have the opportunity to simply check whether their intuitions are true by consulting the equivalent of a handy thermometer. So how then can I claim that they have intuitionindependent means to assess the quality of their intuitions? My argument will proceed as follows. First, I make a number of clarifications concerning the sense in which these means must be independent of intuitions. Then, in section 5, I argue, in the light of these clarifications, philosophers have intuition-independent sources of information about the quality of their intuitions, and the feedback they get from these sources is sufficient to found the expectation that philosopher's intuitions are more reliable than those of novices.

What does the requirement that philosophers have intuition-independent sources of feedback amount to? There are three strong readings which Ryberg might have in mind but which would be too strong. Firstly, one might require that it is possible to determine that an intuitive judgement is false on epistemic grounds in which intuitions play no role. ${ }^{4}$ This is asking too much. Ryberg recognises the norms of mathematical proof as providing the requisite intuition-independent means of quality-assessment for mathematical intuition. However, the epistemic grounds for these norms surely derive from more basic intuitions, e.g., the unacceptability of contradiction. Furthermore, to require a means of assessment with intuition-independent epistemic grounds, one would have to defend some rather substantive position in epistemology (for, it is fairly plausible that intuitions, i.e., non-inferential judgements, play an essential role in the epistemic support for most of our beliefs).

Secondly, one might require independent means that provide,

... direct corroboration of results, i.e., corroboration by evidence from other sources showing directly that a certain result is correct (e.g. my tactile perception of the glass directly corroborates my visual perception of the glass) (Seeger, 2011, p.3)

where the alternative is to allow intuition-independent sources which provide only indirect corroboration,

such as successful application of a method's results in other fields. (p.3).

Seeger makes the point - when disambiguating Weinberg's (2007) use of 'external corroboration' but his point is applicable here too - that to allow only direct forms of corroboration would be too strong. Most mathematical or logical claims are simply not subject to intuition-independent forms of direct corroboration.

Thirdly, one might think that the sources of feedback must be intuition-independent in the sense that they mustn't make use of any intuitions about any domain. ${ }^{5}$ For instance, one might think that rejecting a position because it seems to lead to incoherence doesn't

\footnotetext{
4 Maybe this is what Pust has in mind - in his characterisation of the argument from lack of independent calibration - when he talks of 'independent justification' (Pust, 2014).

5 This is intended to be a weaker reading than the first reading. The first reading rules out feedback in
} 
count as intuition-independent, because one's intuition that incoherence is a sign of falsehood is playing a role. Insofar as this sort of move does rely upon intuitions, it cannot be the case that it does so in a problematic way. Ryberg accepts that logicians' and mathematicians' experience in judging the success of proof strategies refines their intuitions, and rejection on grounds of contradiction is one of the main tools of mathematical proof. Such rejections use the same basic intuitions, and so philosophers should not have to forgo the intuition-independence of reductio arguments, etc. Likewise, a philosopher shouldn't be forbidden appeal to grammatical intuitions where relevant, or to intuitions in any other domain in which she is also expert, so long as, with respect to that domain, there is reason to think her training and experience has refined her intuitions, e.g., philosophers trained in experimental psychology may be permitted (perhaps limited) appeal to their intuitions about psychological claims.

It seems that if we are to permit that expert mathematicians' intuitions are refined by appropriately intuition-independent means, then the sense of intuition-independent we have in mind must be something like the following: a source of direct or indirect corroboration which is not simply one's intuitions from the very same domain.

\section{In Defence of the Quality Assumption}

If this is the sense of intuition-independent sources we insist upon, then Ryberg's contention looses its appeal. It is really not so clear that philosophers do not regularly receive such feedback from intuition-independent sources. In this section, I argue that philosophers receive a substantial amount of such feedback about the quality of their intuitions. I also argue that this feedback is sufficient to found the expectation that philosophers have more reliable intuitions than novices: I argue that philosophers receive more feedback than novices; I also respond to some worries one might have about whether the types of sources I identify provide sufficient feedback.

Weinberg (2007, pp.330-1) provides a useful taxonomy of the ways in which we can obtain confidence that the use of a source of evidence such as intuitions is reliable. ${ }^{6} \mathrm{He}$

which any intuitions play an epistemic role, e.g., some part in the justification. The second reading rules out only actual use of intuitions in the sense of explicit recourse to intuitive claims from any domain.

6 A couple of notes on the relation between my discussion and Weinberg's in order to avoid confusion:

(a) Weinberg talks in terms of 'hope'. I avoid this technical term as it is unnecessary for my purposes.

(b) I present Weinberg's ideas in terms of reliability. Weinberg himself explicitly distances his discussion from claims about reliability. In particular, he says that it is not the mere reliability/unreliability of a source which makes the difference between it being trustworthy or untrustworthy (p.325). That may be right. However, I think we can still talk in terms of reliability. We can say, it is not the reliability of our intuitive capacities which matters, but rather the reliability of our practice of using those capacities.

(c) I talk about three sources. Weinberg talks about four. I don't discuss internal coherence; demonstrating that philosophers get feedback about the internal coherence of intuitionsfeedback concerning intrapersonal and interpersonal agreement-would not help me argue against Ryberg. It is not feedback from an intuition-independent source.

(d) Weinberg and I are involved in distinct debates. Weinberg asks whether intuitions are 'hopeless'. I ask whether philosophers' intuitions should be expected to have been refined to any degree (by certain types of feedback). These debates are connected, but not in a straightforward way. Importantly, my conclusion is compatible with Weinberg's conclusion that intuitions are, for now, 'hopeless'. 
notes three sources of intuition-independent feedback one might have about the quality of a source of evidence.

1. Indirect forms of external corroboration: such as (un)successful application of theories in another field.

2. Detectability of margins: if our practices are sensitive to the conditions in which the source is likely to go wrong/be okay this is a source of confidence - as Kahneman and Klein $(2009,524)$ put it, "True experts, it is said, know when they don't know".

3. Theoretical illumination: having good theories about why the margins are as they are. These are all potential sources of feedback about the quality of intuitions.

All these ways of getting information about the quality of intuitions are available to philosophers. Let me take them in turn. (Weinberg himself argues use of intuitions is problematic precisely because these sources don't give us enough confidence. So, there is some tension between his points and my strategy here which is worth acknowledging-I address the relevant worries he raises in the following.)

\subsection{External Corroboration (including indirect)}

The results of use of moral intuitions can be and are regularly (un)successfully applied in other fields. As Seeger (2011) notes, the results of moral theorising guide our moral and legal practice. Philosophers' intuitions about race, rape, harassment and the punishment of innocents are shaped by consideration of the effect that the application of theories which give weight to certain intuitions rather than others have had on moral and legal practice. For example, those nationalist intuitions I once had have largely dissolved, and introspectively it seems that this is in large part due to thinking about the success/failure of both real societies whose legal/moral practice was largely founded on such intuitions, and to thinking counterfactually about what our society would look like if modified in line with such intuitions. ${ }^{7}$ It is not only intuitions in normative ethics which receive this treatment, but also those about freedom, responsibility, action, causation, etc. ${ }^{8}$

Epistemologists interested in epistemic norms are also interested in how people conduct their epistemic lives in all sorts of domains. Weinberg (2007) addresses this point asking a rhetorical question and answering it:

[Epistemologists] may scratch their heads at this suggestion-what, other than intuition, could speak to the norms that are to guide our believings, reasonings, deliberations, and so on?... We have had a long and fairly welldocumented history of trying out different norms to guide our inquiries, and we can learn from our historians which norms have been active when and what results they seem to have yielded. And we can use our best information about the structure of investigative communities both past and present, as well as what we know about the human agents who operate within them, to speculate counterfactually about what results various sorts of norms might or might not generate for us today. (Weinberg, 2007, p.339)

$7 \quad$ Both are processes which rely on some sort of intuitive judgement. However, as we have noted, this doesn't preclude them from being intuition-independent sources of the appropriate type.

8 I don't deny that a society might do very well despite having a legal/moral system based on false intuitions. Considering such things provides some, but not conclusive, corroborative evidence. The same is true of the indirect corroboration that mathematics gets from successful application in other fields such as engineering and biology. 
Although Weinberg himself is not so optimistic that similar resources are available for other areas of philosophy, I think they clearly are. The metaphysics, e.g., of causation is guided to a degree by scientific progress and empirically-informed understandings of relevant concepts and phenomena. Consider what Paul says when considering the empirical nature and extent of metaphysics:

Metaphysical theories often involve hypotheses about fundamental and general ways of structuring the world, and thus are only indirectly confirmed by their overall success in making sense of ordinary and scientific experience and language. (Paul, 2012)

If a metaphysical account can't make sense of what scientists find and how scientists talk, this is taken to provide a source of feedback that things may not be going so well in the metaphysics. It may be that there are some corners of philosophy in which routine feedback which draws on other domains of enquiry is not available. However, it is not the norm. Although I don't want to put too much weight on it, it is also interesting to note that consideration of the implications of an intuitive position in other areas of philosophy can count as intuition-independent feedback in the right sort of way. Just as thinking about compatibility of one's intuition-based moral theory with one's logical theory can be an appropriate source of feedback, so could thinking about the implications of one's moral theory in metaphysics, for instance.

\subsection{Detectability of Margins}

We are sensitive to the margins of intuitions. We get feedback about the quality of our intuitions due to our sensitivity. We get more such feedback than philosophical novices do. Philosophers are attentive to feedback relating to what types of factor mean intuition is likely to give good/bad results. Philosophers are far more careful about the types of intuition they are willing to give credence than novices-particularly in moral philosophy. In some respects, novices are overly-cautious, philosophers are willing to consider intuitions about unlikely counter-factual cases which can provide interesting illumination, e.g., about internal inconsistency in an account, whereas undergraduates can be very unwilling to consider such cases. In other respects, philosophers exhibit appropriate caution where novices do not. Philosophers try not to let irrelevant factors affect the intuitive judgements they use, e.g., I am aware that trying to accommodate the extent to which the cuddliness of an animal used to alter my intuitions about its intelligence leads to theoretical problems, and my intuitions have grown to be largely immune to this effect when in a reflective context. ${ }^{9}$

Weinberg (2007, pp.335-6) himself thinks there is reason to doubt that intuition has detectability of margins. His main argument concerns the supposed fact that intuitions effectively provide a digital signal, e.g., such and such proposition is true/false, and so lack a richness that typifies sense perception. Let's accept this for the sake of argument. It is true that this provides great reason to think we don't get the same amount of feedback about our intuitions as we do sense perceptions (in this respect). However, it provides no good reason to think we don't get more feedback about our intuitions than

$9 \quad$ My point here is not that philosophers' intuitions are necessarily thereby less prone to distortions or biases. The point is merely that this is evidence of our getting more feedback about the quality of our intuitions due to our greater interest in the margins of our intuitions. This can help refine our intuitions even if it does not make them any less vulnerable to distortion and bias. 
philosophical novices. ${ }^{10}$ Remember, what I am urging here is simply the plausibility of the following point: philosophers' intuitions are generated by processes that have been refined by feedback they receive about what types of factor mean intuition is likely to give good/bad results. ${ }^{11}$

\subsection{Theoretical Illumination}

Do we get feedback about the quality of our intuitions based upon theoretical illumination? Does the amount of feedback we get from this source outstrip the amount novices get? I think the answer to both questions is yes. Please note that saying this doesn't commit us to the idea that we have a fully developed theory of where philosophical intuitions come from. We clearly don't have that (Weinberg makes this point clearly, pp.336-7). But that isn't what is at stake.

Philosophers, especially moral philosophers, have always been interested in theorising about the nature of their methods with respect to intuitions. Sidgwick, Singer, Ross, and Audi all spring to mind. Ryberg alludes to the various evolutionary accounts which have been considered. However, this tendency is far from restricted to moral philosophy. Philosophers tend to think about how intuitions are generated more than any novice and are willing to reject, debunk, or regard with high suspicion, intuitions in certain domains on the basis of their etiology. Explaining away intuitions is a big business and, although the success conditions are not crystal clear, relies on an interest in etiology (see Ichikawa, 2009). ${ }^{12}$ There is good reason to think that philosophers get feedback about the quality of intuitions from careful consideration of how intuitions are generated, certainly more so than philosophical novices. Note that none of this is to deny that philosophers could do with a great deal more theoretical illumination than they have, nor that it would be a good idea to carry out the empirical research necessary to get that illumination.

I should clarify what I take myself to have argued up to this point. My main point is that philosophers get considerably more intuition-independent feedback about the quality of their intuitions than Ryberg countenances, and certainly more than novices. The next question is this: Is this feedback is sufficient to found the assumption that philosophers have more reliable intuitions than novices? Certain empirical findings in the literature on expertise might lead one to think that it is not. Let me say something to dissuade such thoughts.

It is true that the idea that intuition-independent feedback about the quality of intuitions is what is required to refine one's intuitions is one which is well supported by the empirical literature. Weinberg and Crowley (2009) note:

One of the most robust consensus findings of the study of expertise is that

\footnotetext{
10 This is no criticism of Weinberg. He is not engaged in quite the same debate.

11 This doesn't require sources of direct corroboration; information about a lack of internal coherence can be used to infer that the reliability of a source is below a certain level, e.g., intuitions that say p $90 \%$ of the time and not-p the rest of the time are at best $90 \%$ reliable (about whether p).

12 Ryberg admits that one can reject intuitions for theoretical reasons (p.6), but argues this can't provide the right sort of feedback as any such reason must be based on intuitions somewhere down the line. I have ruled out such a strong requirement of independence from intuitions. However, Ryberg's point here is odd for another reason: if Ryberg were right, there would be no obvious need for an expertise defence. The challenge to intuitions relies upon that which Ryberg states can't be done. Intuitions which don't exhibit gender effects are preferable to those which do. Why does the restrictionist accept this? Because the moral properties of an action don't vary depending on who judges it. A theoretical reason which likely rests upon some basic logical intuitions or other.
} 
expert judgments can only become more reliable where experts are readily confronted with clear, reliable feedback on which to train ... The fields in which competent experts routinely develop are those like meteorology, livestock judging, and chess. In such areas, experts are confronted with a truly vast array of cases, with clear verdicts swiftly realized across a wide range of degrees of complexity or difficulty. (Weinberg and Crowley, 2009, p.340)

The basic lesson might seem to be clear: unless philosophers get some comparable feedback, we shouldn't expect philosophers to have more trustworthy intuitions than novices. It is certainly true that philosophers are not confronted with 'a truly vast array of cases with clear verdicts swiftly realized'. It is rare that philosophers have a source of information to turn to which provides a clear, certain and unequivocal verdict: such-andsuch intuition was true/false. However, I argue that this doesn't matter; such feedback is not necessary in order for philosophers' intuitions to be sufficiently refined, as rather more modest forms of feedback (such as those discussed above) are quite sufficient.

One important reason to be cautious about adopting lessons from the empirical literature on expertise, concerns the nature of the debate. Remember that the question which interests us is whether philosophers receive sufficient feedback to enable some significant refinement of their intuitions. The relevant contrast is novices' intuitions. This makes philosophy a little different from the vast majority of the fields discussed in the empirical literature, e.g., stock-picking and weather-forecasting. For, in many other fields, when one is interested in the reliability of experts' intuitions, the relevant contrast class is not the intuitions of novices but rather other tools available to the experts, such as algorithms (see Kahneman and Klein, 2009). This difference is important. Many lessons to be found in the empirical literature, about the necessary amount of feedback needed for experts' intuitions to be plausibly relied upon, are not applicable in our debate, or at least not straightforwardly. Our debate is not about whether philosophers' intuitions are to be expected to be as superior as those of experts in other fields. I don't want or need to defend the claim philosophers' intuitions should be expected to be as superior to the philosophical novice's as the chess grandmasters' are to chess novice's - mutatis mutandis for whichever field you like. ${ }^{13}$

In sum: I have discussed a number of sources of feedback which are available to philosophers - feedback from available sources of external corroboration (construed to include indirect sources), detectability of margins, and theoretical illumination - and there seems to be no good reason to think these sources of feedback are not sufficient to found the expectation that philosophers' intuitions are more reliable than novices'.

\section{Conclusion}

It is important to set aside various claims which I do not wish to endorse and for which I have not argued. I am not claiming philosophers have perfect intuitions, nor that philosophers should get away with this scot-free. Experimental philosophers are right: we should be more careful about our use of intuitions, and make use of available empirical tools to identify issues with intuitions. I certainly don't claim that philosophers' intuitions

13 Indeed I think it is unclear who would want to defend such a claim, and I am not alone: Williamson (2011) expresses a similar sentiment, asking, "who ever claimed that the difference in skill at thought experimentation between a professional philosopher and an undergraduate is as dramatic as the difference in skill at chess between a grandmaster and a beginner?" (p.219). 
should be supposed to be as superior to the philosophical novice's as the grandmaster's are to mine (a complete novice).

What I have done is to provide a limited defence of the expertise defence. I argued for the following claim: the sort of objection to the expertise defence offered by Ryberg (2013) doesn't work. This is important because it threatened to undermine all defences of intuitions in philosophy via appeal to expertise once and for all. I have argued that philosophers' experience does plausibly inform their intuitive capacities. Ryberg fails to see this because he overlooks the simplest account of how philosophers' experience might do this: intuitions about cases are influenced by previous experiences of similar cases. Moreover, I argued that this experience does plausibly refine philosophers' intuitions. Ryberg is wrong to conclude that we don't get the right sort of feedback. We do receive some sort of independent feedback about the quality of intuitions. Ryberg fails to see this because he overlooks a number of sources of feedback we have about the quality of our intuitions. Philosophers do receive sufficient feedback about the quality of their intuitions from available sources of external corroboration (construed to include indirect sources), detectability of margins and theoretical illumination. It is understandable that Ryberg overlooked these sources. It is very tempting to take certain lessons from the empirical literature on the development of expertise which would suggest that such sources are not sufficient for the development of expertise. However, as I have argued, these lessons are not applicable in this particular debate: a debate about whether we should expect the intuitions of philosophers to be more reliable than those of novices. When assessing the expertise defence, comparatively modest improvements upon novices' intuitions are significant in a way that they would not be if, for example, we were comparing philosophers' intuitions to some analogue of a sophisticated weather-predicting supercomputer. We can expect such improvements given the feedback philosophers get (even if this is not sufficient to support the idea that philosophers should be expected to outperform the equivalent of sophisticated weather-predicting supercomputers, or be the philosophical equivalent of a chess grandmaster).

We started with a question: Are the intuitions of philosophers more reliable than the intuitions of people who are not philosophically trained? The question is important. It is important because unless there is good reason to expect the answer to be 'yes' the expertise defence of the use of intuitions in philosophy is a non-starter. I have argued that we should expect philosophical experts to have more reliable intuitions about their field of expertise than novices - just as we expect mathematicians and chess grandmasters to have more reliable intuitions with respect to their domains of expertise. Ryberg's arguments threatened to shut down the expertise defence once and for all. I have shown them to fail. Nonetheless, the reader shouldn't walk away from this paper with the idea that the expertise defence is home and dry. I have provided only a limited defence. The take home message of this paper should be: if the expertise defence fails, it won't be for the reasons Ryberg gives. If the expertise defence doesn't work, it is for other reasons. For instance, it will perhaps be due to the fact that empirical evidence has been found which indicates that philosophers' intuitions are no more reliable than those of philosophical novices (see, e.g., Machery, 2012; Schulz et al., 2011; Vaesen et al., 2013). Or else, it will be due to the success of arguments that the expertise defence requires more than the causality and quality assumptions to get off the ground: for example, that of Weinberg et al. (2010) who makes the case persuasively that (a) the expertise defence requires the assumption that philosophers' training immunizes philosophers' intuitions from specific problematic types of sensitivity, e.g., gender effects, order effects, etc., and 
(b) philosophers' training shouldn't be expected to immunize their intuitions in this way. So the overall prospects of the expertise defence may not be so rosy. But, in any case, the debate over the comparative reliability of experts' and novices' intuitions can't be settled quite as easily as Ryberg hopes.

James Andow

Department of Philosophy

University of Reading

\section{Acknowledgements}

Thanks to David Ingram, Jonathan Tallant and a number of anonymous referees for very helpful comments, as well as to audiences in Nottingham and Sheffield.

Acknowledgement is also due to the AHRC.

\section{References}

Buckwalter, W. (2010). Knowledge isn't closed on saturday: A study in ordinary language, Review of Philosophy and Psychology 1(3): 395-406.

Burnyeat, M. and Barnes, J. (1980). Socrates and the jury: paradoxes in plato's distinction between knowledge and true belief, Proceedings of the Aristotelian Society, Supplementary Volumes 54: 173-206.

Cohen, J. and Nichols, S. (2010). Colours, colour relationalism and the deliverances of introspection, Analysis 70(2): 218-228.

Cova, F. and Pain, N. (2012). Can folk aesthetics ground aesthetic realism?, Monist 95.

Cummins, R. E. (1998). Reflection on reflective equilibrium, in M. DePaul and W. Ramsey (eds), Rethinking Intuition, Rowman \& Littlefield, pp. 113-128.

Gendler, T. and Hawthorne, J. (2005). The real guide to fake barns: A catalogue of gifts for your epistemic enemies, Philosophical Studies 124(3): 331-352.

Gettier, E. (1963). Is justified true belief knowledge?, Analysis 23(6): 121-123.

Goldman, A. (1976). Discrimination and perceptual knowledge, The Journal of Philosophy 73(20): 771-791.

Ichikawa, J. (2009). Explaining away intuitions, Studia Philosophica Estonica 2(2): $94-116$.

Kahneman, D. and Klein, G. (2009). Conditions for intuitive expertise: a failure to disagree, American Psychologist; American Psychologist 64(6): 515-526.

Lewis, D. (1997). Finkish dispositions, Philosophical Quarterly 47(187): 143-158.

Machery, E. (2012). Expertise and intuitions about reference, Theoria 27(1): 37-54. 
Paul, L. A. (2012). Metaphysics as modeling: the handmaiden's tale, Philosophical Studies 160(1): 1-29.

Pust, J. (2014). Intuition, in E. N. Zalta (ed.), The Stanford Encyclopedia of Philosophy, spring 2014 edn.

Rini, R. (2014). Analogies, Moral Intuitions, and the Expertise Defence, Review of Philosophy and Psychology 5(2): 169-181.

Roberts, P., Andow, J. and Schmidtke, K. (2014). Colours, colour relationalism, and the real deliverances of introspection, Erkenntnis 79(5): 1173-1189.

Ryberg, J. (2013). Moral intuitions and the expertise defence, Analysis 73(1): 3-9.

Schulz, E., Cokely, E. T. and Feltz, A. (2011). Persistent bias in expert judgments about free will and moral responsibility: A test of the expertise defense, Consciousness and Cognition 20(4): 1722-1731.

Seeger, M. (2011). The critique from experimental philosophy: Can philosophical intuitions be externally corroborated?, XXII. Deutscher Kongress für Philosophie (conference paper, available at: http://epub.ub.uni-muenchen.de/12575/2/ Seeger-The_Critique_from_Experimental_Philosophy.pdf).

Stich, S. (2010). Philosophy and WEIRD intuition, Behavioral and Brain Sciences 33(2-3): 110-111.

Vaesen, K., Peterson, M. and van Bezooijen, B. (2013). The reliability of armchair intuitions, Metaphilosophy 44(5): 559-578.

Walsh, D. (1996). Fitness and function, The British Journal for the Philosophy of Science 47(4): 553-574.

Weinberg, J. (2007). How to challenge intuitions empirically without risking skepticism, Midwest Studies in Philosophy 31(1): 318-343.

Weinberg, J., Alexander, J., Gonnerman, C. and Reuter, S. (2012). Restrictionism and reflection: Challenge deflected or simply redirected?, The Monist 95(2): 200-222.

Weinberg, J., Gonnerman, C., Buckner, C. and Alexander, J. (2010). Are philosophers expert intuiters?, Philosophical Psychology 23(3): 331-355.

Weinberg, J. M. and Crowley, S. J. (2009). Loose constitutivity and armchair philosophy, Studia Philosophica Estonica 2: 177-195.

Williamson, T. (2011). Philosophical expertise and the burden of proof, Metaphilosophy 42(3): 215-229.

Zamzow, J. L. and Nichols, S. (2009). Variations in ethical intuitions, Philosophical Issues 19(1): 368-388. 